\title{
How Fast Should the Preterm Infant Grow?
}

\author{
Frank R. Greer • Irene E. Olsen
}

Published online: 18 September 2013

(c) Springer Science + Business Media New York 2013

\begin{abstract}
It is clear that the gold standard for weight gain in the preterm infant is to achieve the rate gain of the fetus at the same postconceptional age. This goal is not always easy to achieve, though at the time of discharge most preterm infants are at least growing parallel to the appropriate intrauterine growth curve. Current guidelines for dietary intake do not allow for the necessary "catch-up" growth after the inadequate nutrition of the early weeks of life. Assessment of growth in the neonatal intensive care unit (NICU) should include accurate measurements of weight, length and head circumference. Growth velocity should also be calculated. Anthropometric measurements should be assessed using one of the presently available newer intrauterine growth curves. Postnatal curves showing how preterm infants actually grow are also available and allow for comparison of one preterm infant's growth with other preterm infants. These are particularly useful in the early weeks of life before the infant regains the birth weight and achieves a steady upward growth velocity. The need for catch-up growth is a challenge given the concerns about metabolic programing and adverse outcomes of rapid growth, especially in the preterm infant who is small for gestational age. It is also clear that adequate head growth is very important for neurodevelomental outcome. This article
\end{abstract}

F. R. Greer $(\bowtie)$

Department of Pediatrics, University of Wisconsin School of Medicine and Public Health, Madison, WI, USA

e-mail: frgreer@pediatrics.wisc.edu

\section{E. Olsen}

Department of Biology, College of Science and Mathematics, Kennesaw State University, Kennesaw, GA, USA

e-mail: ieolsen@yahoo.com ends with a suggested individualized practical growth strategy for preterm infants in the NICU.

Keywords Premature infants · Small for gestational age · Growth · Catch-up growth - Intrauterine growth curves . Extrauterine growth curves

\section{Introduction}

Since the beginning of the subspecialty, neonatologists have debated the appropriate or ideal rate of growth for the very low-birth-weight (VLBW) preterm infant (birth weight $<1,500 \mathrm{~g}$ ). The logical standard would be to achieve the rate of growth of the fetus at the same postconceptional age. However, in the 1970s this growth rate was unachievable, and this standard was questioned because the physiological and biochemical aspects of growth of an infant in an isolette are not likely to be the same as those of a fetus floating in a bath of water at $37{ }^{\circ} \mathrm{C}$ with a continuous intravascular delivery of nutrients. Nonetheless, by the 1980s the generally recognized growth standard in the newborn intensive care unit became the rate of weight gain of the fetus at the same postconceptional age. As in the 1970s, however, this goal still remains elusive, particularly in the extremely VLBW infants (birth weight $<1,500 \mathrm{~g}$ ). Ninety percent of 1,660 VLBW infants born in 1994-1995 in the NICHD Neonatal Network were less than the tenth percentile for weight compared to the fetus of the same postconceptional age at the time of hospital discharge [1]. In another study of 24,000 preterm infants (23-34 weeks gestational age) from 124 NICUs born between 1997 and 2000, the prevalence of infants less than or equal to the tenth percentile for weight, length,and head circumference were 28,34 and $16 \%$, respectively, at the 
time of discharge. In this study, as expected, the risk of growth restriction increased dramatically with decreasing gestational age and birth weight. Thus, for 866 infants born at 27 weeks gestation, the prevalence of infants less than the tenth percentile for weight, length and head circumference were 46,67 and $26 \%$, respectively, at the time of discharge [2]. This is despite improved overall nutrition management, which now includes instituting trophic feedings and total parenteral nutrition in the first 2 days of life.

At the time of discharge, preterm infants are typically growing parallel to the intrauterine rate; however, the inadequate nutrition of the early weeks of life combined with the failure of current nutritional guidelines to allow for the necessary "catch-up" growth do not result in the achievement of the comparable fetal weight at discharge for nearly all infants with a gestational age less than 28 weeks (Clark RH, personal communication, May 2013). Data again from the NICHD Neonatal Research Network show that even at 30 months of chronological age, $32 \%$ of infants with a birth weight of less than 1,000 $\mathrm{g}$ are less than the National Center for Health Statistics (NCHS) tenth percentile for weight, and $24 \%$ are less than the NCHS tenth percentile for length [3]. In addition, $21 \%$ are less than the NCHS tenth percentile for head circumference. Studies of even longer term outcomes show that, compared to their peers with a birth weight $>2,499 \mathrm{~g}$, VLBW infants even at 14 years of age remain smaller for height, weight and head circumference [4].

\section{Assessment of Growth in the NICU}

Ideally, the assessment of growth in the NICU should start with accurate and routine measurements of weight (daily), length (weekly) and head circumference (weekly) at a minimum. These data should be used to calculate growth velocity (in $\mathrm{g} / \mathrm{kg} / \mathrm{day}$ and $\mathrm{cm} / \mathrm{week}$, respectively) and plotted on size-for-age intrauterine growth curves (discussed below) around the same time each week. Recent data suggest that the growth assessment of preterm infants should also include a measure of body proportionality, such as ponderal index (weight/length ${ }^{3}$ ) or body mass index $\left(\mathrm{BMI}\right.$ or weight/length ${ }^{2}$ ), as this provides a more complete picture of growth status than is provided by size-for-age alone [5]. Growth status should in turn be used to make informed nutrition care decisions on a daily basis for each infant in the NICU.

\section{Growth Velocity}

It is important to calculate growth velocity in the same way each week and for each infant in the NICU (e.g., day
14 weight minus day 7 weight in grams, divided by 7 days, and then divided by day 14 weight in kilograms) for a fair comparison of growth rates within and between infants. There is no generally accepted standardized calculation for growth velocity in the NICU so this should be taken into consideration when reviewing the literature on this subject. Growth velocity rates of approximately $15 \mathrm{~g} / \mathrm{kg} /$ day in weight, $\sim 1 \mathrm{~cm} /$ week in length and $\sim 0.5-1 \mathrm{~cm} /$ week in head circumference are commonly used as goal rates for preterm infants in the NICU; however, data from recent studies suggest these rates may underestimate current fetal growth and do not account for the changes in growth velocity as postmenstrual age at birth and postnatal age advance. Further research is needed to determine if NICU growth goals need to be redefined. However, the growth velocity typically changes little after birth weight has been regained and the infant is in the "eat and grow" phase of NICU hospitalization $[6 \bullet, 7 \bullet]$.

\section{Growth Curves: Intrauterine Growth Curves}

Two types of growth curves are available for the assessment of preterm infant growth: intrauterine curves and postnatal curves. Intrauterine growth curves are generally accepted as the best available tool for growth assessment in the neonatal intensive care unit (NICU) at birth and postnatally $[6 \cdot, 8-18]$. These curves are created using crosssectional anthropometric birth data for each gestational age. As a result, intrauterine growth curves represent intrauterine or fetal growth, the generally accepted goal for preterm infant growth after birth, as best we can estimate it at this time. Using birth data of preterm infants as an indicator of intrauterine growth is not perfect, because these infants are often born smaller than if they had remained in utero without the complications associated with premature birth $[15,19,20]$, but there is no method to directly measure fetal weight while still in utero. Thus, this method remains the best available option [21-23].

There are many examples of intrauterine growth curves, but only some include weight, length and head circumference $[6 \cdot 10,12,14-16]$. Many of the newer intrauterine curves include only weight-for-age curves $[8,9,11,13,17$, 24]; the lack of length and head circumference-for-age curves limits the usefulness of these curves in the NICU for assessing growth and overall nutritional status. For preterm infants after discharge from the NICU, growth measurements are plotted using a corrected age for up to the first 3 years of life [25]. The WHO Child Growth Standards (or WHO curves, http://www.who.int/childgrowth/standards/ en/) are recommended from 0 to 24 months, and the CDC 2000 growth charts (http://www.cdc.gov/growthcharts/ clinical_charts.htm) should be used thereafter, using the 
corrected age for up to 3 years of life (chronological age) in preterm infants.

A recent set (2010) of intrauterine growth curves (weight, length and head circumference for age) from Olsen et al. [6•] (https://www2.aap.org/sections/perinatal/ PDF/GrowthCurves.pdf) offers some advantages for use in the USA over other published intrauterine curves. These curves are gender specific because of size differences and were created using newer data (1998-2006) and a large US sample of 130,111 singleton infant NICU admissions that approximates the current racial distribution of US births (15.7 \% Black, $24.4 \%$ Hispanic, $50.6 \%$ White and $9.3 \%$ other); these curves were also validated using an separate sample from the same data set $(n=127,744)$. Comparable to other curve data, the clinical length measurements for these curves may have been done with either a tape measure or length board, which likely has a negative impact on the quality of these data; however, it is assumed that the large sample size may cancel out most of the random errors in the clinical growth measurements. The use of research quality growth measurements for the creation of growth curves such as these would be ideal, but a large database of this type does not exist within the US.

The Olsen curves are gaining acceptance in the US and abroad. The new definition for small-for-gestational age (SGA) as defined by the Olsen [26•] weight-for-age growth curves was recently validated by a study from the NICHD Neonatal Research Network. In their sample of very preterm infants ( $<27$ weeks GA at birth, 2006-2008 data), the Olsen curves appropriately assigned infants into the SGA group (i.e., $13 \%$ of the infants were SGA compared to the expected $10 \%$ ) and found that these infants were at higher risk for morbidity and mortality, as would be expected.

Of note, gender-specific BMI-for-age intrauterine curves to complete the set of gender-specific size-for-age intrauterine growth curves from Olsen et al. are in development. In addition, reformatted versions of the Olsen intrauterine curves are now available along with the appropriate WHO postnatal growth curves (http://www.pediatrix.com/work files/NICUGrowthCurves7.30.pdf). Note the Olsen curves and WHO curves are not merged in the reformatted version since each was created using an independent set of data.

The 2003 Fenton [12] unisex curves (http://ucalgary.ca/ fenton/2003chart) commonly used in NICUs today for preterm infants differ from the Olsen gender-specific curves in a number of ways. The 2003 Fenton [13] curves are based on non-US data: Canadian data were used to create the weight-for-age curves, and a combination of Swedish [27] and Australian data [28] was used for the length- and head circumference-for-age curves. The Fenton curves also are a combination of intrauterine and postnatal curves. Between approximately 36 and 46 weeks, the preterm (or intrauterine) portion of the Fenton curves were manually smoothed to connect to the post-term portion of the growth curves: i.e., originally the 2,000 growth curves from the Centers for Disease Control and Prevention (CDC) [12, 29] and, more recently, the WHO curves [30]. In 2013, Fenton et al. [31•] published an updated set of growth curves and included the WHO curves on the same graph (http://ucalgary.ca/fenton/2013chart). These curves are now gender specific and created using six published data sets for the intrauterine portion of the curves: five nonUS data sets (Canada [13], Australia [32], Italy [33], Scotland [34] and Germany [35]) and one US data set [6॰]. Two of these data sets were used for the length and head circumference-for-age curves $[6 \bullet, 33]$. Similar to the 2003 Fenton curves, the 2013 Fenton curves connect and smooth the intrauterine curves to the WHO curves. It is important to note that connecting and smoothing growth curves from independent sets of data distorts the curve percentiles. An example of this distortion can be observed in Fig. 5 of the Fenton et al. [31•] paper (http://www.biomedcentral.com/ 1471-2431/13/59).

Curves published by Lubchenco [14, 15] and Babson [10] are also in use (especially in newborn nurseries), but both are based on small, homogeneous samples of infants from single hospitals born several decades ago and are therefore of limited usefulness in current US NICUs and nurseries.

\section{Growth Curves: Postnatal Growth Curves}

Postntatal growth curves [36-38] have been created using longitudinal data with repeated anthropometric measurements over time. As a result, postnatal curves illustrate actual growth (i.e., descriptive curves) over time, not ideal growth (prescriptive curves) of preterm infants. As nearly all extremely low-birth-weight infants $(<1,000 \mathrm{~g}$ birth weight) experience significant growth restriction during their NICU hospitalization, falling below the percentile of their weight at birth, postnatal curves also allow for the comparison of one preterm infant's growth to the growth of other preterm infants and therefore may serve as useful adjunct assessment tools to the intrauterine growth curves. One series of postnatal curves widely used for former preterm infants is the Infant Health and Development Program (IHDP) Growth Percentiles (http://www.ped.med.utah.edu/pedsintranet/clinical/ references/growthCharts/growthCharts.htm) for low-birthweight and very low-birth-weight infants. These have historically been provided by a maker of infant formula. Although based on data that are quite old at this time, there is no comparable replacement for use in the NICU. As the intrauterine growth rate is frequently not achieved in preterm infants until term-equivalent gestational age is approached, or in the case of larger preterm infants not until after the time of discharge, postnatal curves may be useful $[1,39]$. 
Growth Curves: Body Proportionality, Body Composition

In an ideal world, it would also be appropriate to include intrauterine curves of body composition for assessment of growth in the NICU. Concerns for rapid postnatal growth, fat accumulation and their potentially adverse effects have increased interest in the composition of postnatal growth [40-42]. However, accurate measurements of body composition are not routinely available for infants in the NICU, and contemporary proxies such as curves of weight for length, BMI or even skin fold thicknesses are not yet available in this population. As noted above, gender-specific BMI-for-age curves are currently in development based on the large, recent, racially diverse US data set used for the Olsen size-for-age intrauterine growth curves [6•]. There is also the potential to use biomarkers such as IGF-1 or genetic markers to assess growth in this infant population in the future.

\section{The Need for Catch-Up Growth}

As noted above, though VLBW preterm infants typically parallel the intrauterine growth rate at the time of discharge, they remain well below their birth percentiles for growth. This is despite improvements in nutrient intake with modern TPN solutions, special formulas and human milk fortifiers for preterm infants, and initiation of both TPN and trophic feedings in the first day or two of life. Current dietary recommendations do not take into account the need for catch-up growth. In addition neonatologists are currently conflicted by the Barker hypothesis and its relationship to metabolic programming as well as the so-called growth acceleration hypothesis for preterm infants.

In the Barker hypothesis as applied to the preterm infant normally grown at birth, the early postnatal weeks of nutritional deprivation are a critical period in life. Historically, this has been a period in which the diet is high in carbohydrates and low in protein, which is then often followed by a period of high fat intake. This period of inadequate nutrition then theoretically leads to adverse metabolic programming, which carries on into adulthood. These concerns subsequently led to the institution of "aggressive nutritional support" of the VLBW infant very early in life, which includes increased protein intake and presumably an increased rate of growth and a decreased time in which to return to birth weight (see accompanying paper by W.W. Hay) [39]. However, there may be adverse outcomes of increased growth rates in preterm infants as well as protein intakes exceeding that which can be utilized for growth. Indeed, it has been speculated that an accelerated growth rate in premature infants is a common denominator for an increased risk for cardiovascular disease later in life. This was fueled by the publication by Singhal and Lucas [43] proposing the "Growth Acceleration Hypothesis" for preterm infants, concluding that a slower somatic growth rate may be beneficial. On the other hand, it is well known in the preterm infant that there is a strong association between delayed head growth and adverse neurodevelopmental outcome [7•,44].

For the AGA preterm infant in the NICU, both high and low nutrient intakes, as well as fast or slow rates of growth, may have either some long-term beneficial or adverse effects. From the available evidence at this time, it seems reasonable to increase the nutrient intake of AGA premature infant in the first week of life. On the other hand, there is no evidence to support an increased rate of growth that results in a weight gain that exceeds the birth percentile for weight. Regarding increased risk for adult metabolic syndrome, available data show that effects of an increased growth rate and even prematurity itself are relatively small compared to the impact of other risk factors that act as confounders according to a recent meta-analysis [45]. The effects of parental weight, rate of growth later in childhood and various lifestyle factors have a far greater impact on adult metabolic syndrome than being born prematurely. Furthermore, studies in children looking for evidence of either prenatal or postnatal programming for weight and insulin resistance have found little evidence for early metabolic programming [46-48]. From the most recent meta-analysis of adult studies (ages 21-39 years, with a few subjects $>30$ years), preterm birth compared to term birth is at best associated with the 3-4 $\mathrm{mm}$ increase in adult systolic BP (males $>$ females). No real differences were seen for diastolic BP, lipid profiles, fasting glucose, insulin, arterial thickness/endothelial dysfunction, BMI and percentage fat mass [49•]. In contrast to the minimal effect of prematurity on adult metabolic syndrome, nearly every neurodevelopmental study in preterm infants that has looked at head size has found an inverse relationship between head size and the degree of neurodevelopmental delay $[7 \cdot, 44]$.

When it comes to catch-up growth, the SGA term or preterm infant is a special case and is clearly more prone to developing elements of adult metabolic syndrome later in life $[50,51]$. This harks back to the ideas of David Barker and the concept of the 'thrifty phenotype,' which has been related to the studies of pregnant women and their infants during the Dutch famine in the final years of WWII [52]. In this hypothesis, the SGA infant is "scaled down" metabolically to tolerate a state of malnutrition, which then increases the survival of the fetus in an environment of deprivation. It then follows for an infant who is "metabolically programmed" for life to deal with less, and who is subsequently born into an environment with a relative 
excess amount of nutrients, that there is an increased risk for obesity and metabolic syndrome. The ideal growth trajectory for the SGA infant is unknown, but there is clearly a need for catch-up head growth given the high potential for developmental delays in this population. This is an unresolved dilemma for the practicing neonatologist at this time.

\section{Summary: An Individualized Practical Growth Strategy for the Preterm Infant in the NICU}

It was not the purpose of this article to review the nutrient requirements of the preterm infant or the method of nutrient delivery in the NICU. This information is readily available elsewhere and for the most part current dietary recommendations for preterm infants are best guesses and methods of nutrient delivery are largely based on expert opinion $[53,54]$. On the other hand, there is a growing tendency for a more individualized approach for nutritional support for premature infants. In concluding this article, the author would like offer some suggestions that may be of service to other NICUs in developing a more individualized approach for the preterm infant. In other words, "this is how we do it," and nothing more:

Proposed guiding principles for individualized nutritional support for adequate growth in preterm infants in the NICU:

1. Standardized feeding protocols as much as possible with buy-in from all members of the NICU team.

2. Maintain weight, length and head growth charts, which are reviewed daily on rounds using the electronic medical record, by plotting the infant's individual growth data on an available intrauterine growth curve.

3. For preterm AGA infants, achieve and then maintain the rate/velocity of growth that will achieve and then maintain the birth percentile for the infant's birth weight. Length per centile should also be utilized if length boards are available in the NICU for accurate weekly measurements. If the birth percentiles for weight or length are exceeded, consider decreasing nutrient intake.

4. Provide energy/nutrients for catch-up growth when weight in the NICU falls below the birth centile and the infant is not in a catabolic state associated with concurrent illness. This can be done by increasing overall calories and protein intake.

5. For SGA infants, similarly maintain daily growth charts and at a minimum maintain the birth percentile for a given birth weight. The need for catch-up growth is more important than that in the term infant for neurological outcome, especially for symmetrically
SGA preterm infants. Achieving the tenth percentile for weight for a given postconceptional age by increasing nutrient intake is a reasonable end point at this time, assuming head growth will follow.

6. A neonatal nutritionist should make daily assessments of the preterm infant's nutritional status to monitor adherence to a feeding protocol and to make recommendations for appropriate growth.

\section{Compliance with Ethics Guidelines}

Conflict of Interest Frank R. Greer has no conflict of interest. Dr. Irene E. Olsen is the author of the intrauterine growth curves in Ref. [6].

Human and Animal Rights and Informed Consent This article does not contain any studies with human or animal subjects performed by any of the authors.

\section{References}

Articles of particular interest, published recently, have been highlighted as:

- Of importance

1. Ehrenkranz RA, Younes N, Lemons JA, Fanaroff AA, Donovan E, Wright LL, Katiskiotis V, Tyson JE, Oh W, Shankaran S, Bauer CR, Korones SB, Stoll BJ, Stevenson DK, Papile LA. Longitudinal growth of hospitalized very low birth weight infant. Pediatrics. 1999;104:280-9.

2. Clark RH, Thomas P, Peabody J. Extrauterine growth restriction remains a serious problem in the prematurely born neonates. Pediatrics. 2003;111:986-90.

3. Dusick A, Poindexter B, Ehrenkranz R, et al. Catch-up growth in extremely low birth weight infants in early childhood. E-PAS 2005; $57: 1450$.

4. Ford GW, Doyle LW, Davis NM, et al. Very low birth weight and growth into adolescence. Arch Pediatr Adolesc Med. 2000;154:778-84.

5. Olsen IE, Lawson ML, Meinzen-Derr J, Sapsford AL, Donovan $\mathrm{EF}$, Morrow AL. Use of body proportionality index for growth assessment of preterm infants. J Pediatr. 2009;154:486-91.

6. - Olsen IE, Groveman SA, Lawson ML, Clark RH, Zemel BS. New intrauterine growth curves based on United States data. Pediatrics. 2010;125(2):e214-e224. New intrauterine growth curve for preterm infants based on US data.

7. - Ehrenkranz RA, Dusick AM, Vohr BR, et al. Growth in the neonatal intensive care unit influences neurodevelopmental and growth outcomes of extremely low birth weight infants. Pediatrics 2006;117:1253-61. Newest data from the Neonatal Network on the impact of growth on neurodevelopmental outcomes.

8. Alexander GR, Himes JH, Kaufman RB, Mor J, Kogan M. A United States national reference for fetal growth. Obstet Gynecol. 1996;87(2):163-8.

9. Arbuckle TE, Wilkins R, Sherman GJ. Birth weight percentiles by gestational age in Canada. Obstet Gynecol. 1993;81(1):39-48.

10. Babson SG, Benda GI. Growth graphs for the clinical assessment of infants of varying gestational age. J Pediatr. 1976;89(5):814-20.

11. Bonellie S, Chalmers J, Gray R, Greer I, Jarvis S, Williams C. Centile charts for birthweight for gestational age for Scottish singleton births. BMC Pregnancy Childbirth. 2008;8:5. 
12. Fenton TR. A new growth chart for preterm babies. Babson and Benda's chart updated with recent data and a new format. BMC Pediatr. 2003;3:13.

13. Kramer MS, Platt RW, Wen SW, et al. A new and improved population-based Canadian reference for birth weight for gestational age. Pediatrics. 2001;108(2):e35.

14. Lubchenco LO, Hansman C, Boyd E. Intrauterine growth in length and head circumference as estimated from live births at gestational ages from 26 to 42 weeks. Pediatrics. 1966;37(3):403-8.

15. Lubchenco LO, Hansman C, Dressler M, Boyd E. Intrauterine growth as estimated from liveborn birth-weight data at 24 to 42 weeks of gestation. Pediatrics. 1963;32:793-800.

16. Niklasson A, Albertsson-Wikland K. Continuous growth reference from 24th week of gestation to 24 months by gender. BMC Pediatr. 2008;8:8.

17. Oken E, Kleinman KP, Rich-Edwards J, Gillman MW. A nearly continuous measure of birth weight for gestational age using a United States national reference. BMC Pediatr. 2003;3:6.

18. Riddle WR, DonLevy SC, Qi XF, Giuse DA, Rosenbloom ST. Equations to support predictive automated postnatal growth curves for premature infants. J Perinatol. 2006;26(6):354-8.

19. Bukowski R, Gahn D, Denning J, Saade G. Impairment of growth in fetuses destined to deliver preterm. Am J Obstet Gynecol. 2001;185(2):463-7.

20. Doubilet PM, Benson CB, Wilkins-Haug L, Ringer S. Fetuses subsequently born premature are smaller than gestational agematched fetuses not born premature. J Ultrasound Med. 2003; 22(4):359-63.

21. Ehrenkranz RA. Estimated fetal weights versus birth weights: should the reference intrauterine growth curves based on birth weights be retired? Arch Dis Child Fetal Neonatal Ed. 2007; 92(3):161-2.

22. Moyer-Mileur LJ. Anthropometric and laboratory assessment of very low birth weight infants: the most helpful measurements and why. Semin Perinatol. 2007;31(2):96-103.

23. Rao SC, Tompkins J. Growth curves for preterm infants. Early Hum Dev. 2007;83(10):643-51.

24. Riddle WR, Donlevy SC, Lafleur BJ, Rosenbloom ST, Shenai JP. Equations describing percentiles for birth weight, head circumference, and length of preterm infants. J Perinatol. 2006;26(9): 556-61.

25. Engle WA. Age terminology during the perinatal period. Pediatrics. 2004;114(5):1362-4.

26. - DeJesus LC, Pappas A, Shankaran S, Li L, Das, A, Bell EF, Stoll BJ, Laptook AR, Walsh MC, Hale EC, Newman NS, Bara R, Higgins RD, Eunice Kennedy Shriver National Institute of Human Development Neonatal Research Network. Outcome of small for gestational age infants born at $<27$ weeks gestation. J Pediatr. 2013;161:70-4.e1-e2. Latest data from the Neonatal Network specifically regarding outcomes of SGA infants.

27. Niklasson A, Ericson A, Fryer JG, Karlberg J, Lawrence C, Karlberg P. An update of the Swedish reference standards for weight, length and head circumference at birth for given gestational age (1977-1981). Acta Paediatr Scand. 1991;80(8-9): 756-62.

28. Beeby PJ, Bhutap T, Taylor LK. New South Wales populationbased birthweight percentile charts. J Paediatr Child Health. 1996;32(6):512-8.

29. Kuczmarski RJ, Ogden CL, Grummer-Strawn LM, et al. CDC growth charts: United States. Adv Data. 2000;314:1-27.

30. WHO Multicentre Growth Reference Study Group. WHO child growth standards based on length/height weight and age. Acta Paediatr Suppl. 2006;450:76-85.

31. - Fenton TR, Kim JH. A systematice and meta-analysis to revise the Fenton growth chart for preterm infants. BMC Pediatr.
2013;13:59. Revision of the widely used Fenton curves for postnatal growth of the preterm infant.

32. Roberts CL, Lancaster PA. Australian national birthweight percentiles by gestational age. Med J Aust. 1991;170:114-8.

33. Bertino E, Spada E, Occhi L, Coscia A, Giuliardi L, Gill G, Bona G, Fabris C, De CM, Milani S. Neonatal anthropometric charts: the Italian neonatal study compared with other European studies. J Pediatr Gastroenterol Nutr. 2010;51:353-61.

34. Bonelie S, Chalmers J, Gray R, Greer I, Jarvis S, William C. Centile charts for birthweight for gestational age for Scottish singleton births. BMC Pregnancy Childbirth. 2008;8:5.

35. Voigt M, Guthman F, Hesse V, Gorlich Y, Straube S. Somatic classification of neonates based on birth weight, length, and head circumference: quantification of the effects of maternal BMI and smoking. J Perinatal Med. 2011;39:291-7.

36. Ehrenkranz RA, Younes N, Lemons JA, Fanaroff AA, Donovan EF, Wright LL, et al. Longitudinal growth of hospitalized very low birth weight infants. Pediatrics. 1999;104(2 Pt 1):280-9.

37. Guo SS, Roche AF, Chumlea WC, Casey PH, Moore WM. Growth in weight, recumbent length, and head circumference for preterm low-birthweight infants during the first three years of life using gestation-adjusted ages. Early Hum Dev. 1997;47(3): 305-25.

38. Guo SS, Wholihan K, Roche AF, Chumlea WC, Casey PH. Weight-for-length reference data for preterm, low-birth-weight infants. Arch Pediatr Adolesc Med. 1996;150(9):964-70.

39. Hay WW. Aggressive nutrition of the preterm infant. Curr Pediatr Rep. 2013; in press.

40. Ong KK. Rapid infancy weight gain and subsequent obesity: systematic reviews and hopeful suggestions. Acta Paediatr. 2006; 95:904-8.

41. Yeung MY. Postnatal growth, neurodevelopment and altered adiposity after preterm birth-from a clinical nutritional perspective. Acat Paediatr. 2006;95:909-17.

42. Johnson MJ, Wootton SA, Leaf AA, Jackson AA. Preterm birth and body composition at term equivalent age: a systematic review and meta-analysis. Pediatrics. 2012;130:e640-9.

43. Singhal A, Lucas A. Early origins of cardiovascular disease: is there a unifying hypothesis? Lancet. 2004;363:1642-5.

44. Franz AR, Pohlandt F, Bode H, Mihatsch WA, Sander S, Kron M, Steinmacher J. Intrauterine, early neonatal, and postdischarge growth and neurodevelopmental outcomes at 5.4 years in extremely preterm infants after intensive neonatal nutritional support. Pediatrics. 2009;123:e101-9.

45. Greer FR. Long-term adverse outcomes of low-birth-weight, increased somatic somatic growth rates, and alterations of body composition in the premature infant: review of the evidence. J Ped Gastroenterol Nutr. 2008;45:S147-52.

46. Hack M, Schluchter M, Cartar L, et al. Blood pressure among very low birth weight $(<1.5 \mathrm{~kg})$ young adults. Pediatr Res. 2005;58:677-84.

47. Keijzer-Veen MG, Finken MJJ, Nauta J, et al. Is blood pressure increased 19 years after intrauterine growth restriction and preterm birth? A prospective follow-up study in the Netherlands. Pediatrics. 2005;116:725-31.

48. Bonamyå $\mathrm{AKE}$, Bendito $\mathrm{A}$, Martin $\mathrm{H}$, et al. Preterm birth contributed to increased vascular resistance and high blood pressure in adolescent girls. Pediatr Res. 2005;58:845-9.

49. - Parkinson JRC, Hyde MJ, Gale C, Santhakumaran S, Modi N. Preterm birth and the metabolic syndrome in adult life: a systematic review and meta-analysis. Pediatrics. 2013;131:e1240e1263. Most recent meta-analysis of evidence of the influence of early metabolic programing later in life.

50. Meas T, Deghmoun S, Alberti C, Carreira E, Armoogum P, Chevenne D, Levy-Marchal C. Independent effects of weight 
gain and fetal programming on metabolic complications in adults born small for gestational age. Diabetologia. 2010;53:907-13.

51. Hernandez MI, Mericq V. Metabolic syndrome in children born small-for-gestational age. Arq Bras Endocrinol Metabol. 2011; 55:583-9.

52. Barker DJ, Gluckman PD, Godfrey KM, et al. Fetal nutrition and cardiovascular disease in adult life. Lancet. 1993;341:938-41.
53. Tsang RC, Uauy R, Koletzko B, Zlotkin SH, eds. Nutrition of the preterm infant: scientific basis and practical guidelines. 2nd ed. Cincinnati, OH: Digital Educational Publishing Inc; 2005.

54. American Academy of Pediatrics Committee on Nutrition: Nutritional needs of the preterm infant. In: Kleinman RE, Greer FR, editors. Pediatric Nutrition. 7th ed. Elk Grove Village, IL: American Academy of Pediatrics; 2013. 